\title{
A Hybrid Heuristic and Evolutionary Algorithm for Distribution Substation Planning
}

\author{
Seyed Mahdi Mazhari, Student Member, IEEE, Hassan Monsef, and Rubén Romero, Senior Member, IEEE
}

\begin{abstract}
This paper presents an enhanced evolutionary algorithm to solve the static distribution substation planning problem within large distribution networks. It is based on a deterministic heuristic algorithm to find the approximate substation service areas for each substation and an expert selection strategy that increases the convergence chance to a global optimal solution. The introduced algorithm takes different electrical constraints such as voltage drops, power flow, radial flow constraints, and all prevalent cost indices into consideration. In addition, effects of unreliability within network feeders and substations are investigated on the obtained layouts. The developed method is applied to four benchmark test systems and an actual large-scale distribution system with about 140000 customers, followed by a discussion on results.
\end{abstract}

Index Terms-Distribution expansion planning (DEP), evolutionary algorithm (EA), heuristic algorithm, substation planning.

\section{NOMENCLATURE}

The notation used throughout this paper is reproduced below for quick reference.

\section{Sets}

$\Omega_{l} \quad$ Set of load points (electrical domains).

$\Omega_{i}^{\mathrm{ED}} \quad$ Set of customers within the $i$ th electrical domain.

$\Omega_{s} \quad$ Set of existing and candidate substations.

$\Omega_{\mathrm{ss}} \quad$ Set of selected substations (existing and proposed).

$\Omega_{i, t}^{s} \quad$ Set of substations that can supply load point $i$ at $t$ th iteration.

$\Omega_{l, t}^{\mathrm{un}} \quad$ Set of unsupplied load points at $t$ th iteration.

$\Omega_{l, i t}^{\text {sup }}$ Set of costs associated with supplying load point $i$ from $\Omega_{i, t}^{s}$ in ascending order.

$\Omega_{s, i}^{\operatorname{tr}} \quad$ Set of allowed standard size transformers in substation $i$.

$\Omega_{\mathrm{ss}, i}^{\operatorname{tr}} \quad$ Set of selected transformers in substation $i$.

Manuscript received July 2, 2013; accepted October 19, 2013. Date of publication November 28, 2013; date of current version November 20, 2015. This work was supported in part by the Research Center of Power System Operation and Planning Studies, University of Tehran and in part by the Brazilian Institutions Conselho Nacional de Desenvolvimento Cientifico e Tecnológico and Fundação de Amparo a Pesquisa do Estado de São Paulo.

S. M. Mazhari is with the School of Electrical Engineering, Amirkabir University of Technology, Tehran, Iran, and also with the School of Electrical and Computer Engineering, University of Tehran, Tehran, Iran (e-mail: mazhari@aut.ac.ir).

H. Monsef is with the School of Electrical and Computer Engineering, University of Tehran, Tehran, Iran (e-mail: hmonsef @ut.ac.ir).

R. Romero is with the Faculdade de Engenharia de Ilha Solteira, Departamento de Engenharia Elétrica, Universidade Estadual Paulista "Julio de Mesquita Filho," 15385-000 Ilha Solteira-SP, Brazil (e-mail: ruben@dee.feis. unesp.br).

Digital Object Identifier 10.1109/JSYST.2013.2290973

\section{Constants}

$C_{l} \quad$ Per unit cost of energy loss (in $\$ / \mathrm{kWh}$ ).

$C^{\mathrm{SI}} \quad$ Cost of supply interruption (in $\$ / \mathrm{kWh}$ ).

$n_{y} \quad$ Number of years in planning period (in years).

PW Present worth factor.

Infr Inflation rate.

Intr Interest rate.

$\psi^{\text {min }}$ Minimum permissible loading percentage of substations.

$\psi^{\max } \quad$ Maximum permissible loading percentage of substations.

$\alpha \quad$ Number of hours in a year (8760).

$\gamma \quad$ Loss factor.

$\kappa \quad$ Load factor.

$d_{i j} \quad$ Distance between nodes $i$ and $j$ (in kilometers).

$\lambda_{i j} \quad$ Failure rate in branch $i-j$ (in failures per kilometer per year).

$\tau_{i j} \quad$ Average repair time in branch $i-j$ (in hours).

$S_{j}^{l} \quad$ Expected load demand at node $i$ (in megavoltamperes).

$\Delta V_{\max } \quad$ Maximum allowed voltage drop.

$V_{n} \quad$ Nominal voltage magnitude (in volts).

$n_{\text {pop }} \quad$ Total number of populations in the evolutionary algorithm (EA).

$k_{\text {sel }} \quad$ Selection rate of the EA.

$\left(x_{i}, y_{i}\right)$ Coordinates of node $i$ (in kilometers).

Functions

$P V_{i}^{t} \quad$ Priority value of load point $i$ at $t$ th iteration.

$P_{i j}^{\text {loss }} \quad$ Copper losses of feeder located between nodes $i$ and $j$ (in kilowatts).

Fit $_{\text {SEP }}$ Fitness function of the substation expansion planning (SEP) problem.

$C_{i j, t}^{\text {sup }} \quad$ Total cost associated with supplying load point $i$ from substation $j$ at instant $t$ (in \$).

\section{Variables}

$C_{i}^{S} \quad$ Total expansion and maintenance costs of substation $i$ within the planning horizon (in \$).

$C_{i j}^{F}\left(\rho_{k}\right) \quad$ Construction/reinforcement cost of feeder located between nodes $i$ and $j$ by conductor $\rho_{k}$ (in $\$ / \mathrm{km}$ ).

$I_{\rho_{k}}^{\max } \quad$ Maximum allowable current of feeder of type $\rho_{k}$ (in amperes).

$r_{i j} \quad$ Resistance per length of feeder constructed between nodes $i$ and $j$ (in ohms per kilometer).

$z_{i j} \quad$ Impedance per length of feeder constructed between nodes $i$ and $j$ (in ohms per kilometer). 
$P_{i j}^{c u} \quad$ Copper losses in the $j$ th transformer of substation $i$ at the rated loading (in kilowatts).

$P_{i j}^{\text {iron }} \quad$ Iron losses in substation transformer $i$ (in kilowatts).

$S_{i}^{S} \quad$ Total power provided by substation $i$ (in megavoltamperes).

$C S_{i} \quad$ Selected capacity of substation $i$ (in megavoltamperes).

$\beta_{i j} \quad$ Binary decision variable that is equal to 1 if substation $i$ supplies load point $j$ and 0 otherwise.

$u_{i}^{s} \quad$ Average outage time of substation $i$ (in hours).

$\omega_{i j, t} \quad$ Approximate worth of supplying load point $i$ from the $j$ th suitable substation at $t$ th iteration.

$C_{i j, t} \quad$ Total cost associated with supplying load point $i$ from the $j$ th suitable substation at instant $t$ (in $\$$ ).

$\vartheta_{i} \quad i$ th chromosome of the EA population.

\section{INTRODUCTION}

D ISTRIBUTION expansion planning (DEP) is such an important issue in power system planning that the proposed structure must obtain optimal performance in addition to respecting technical constraints. This is a complicated problem, and efficient optimization algorithms are needed to solve it. DEP is usually divided into two optimization problems: SEP and optimal feeder routing [1]. Since the energy injected into a distribution network is mostly supplied through distribution substations, these play an intermediary role between transmission and distribution systems [2]. Usually, depending on the geographic distribution of actual consumers, the service area of a power distribution system is divided into many small irregular areas called "electrical domains." Each domain has a load point showing the load consumption of customers in this domain [1]. Moreover, some candidate locations exist for the construction of new substations, and there is the possibility of expanding some existing ones. The aim of SEP is to determine substation locations, capacity, associated service areas, and equipment installation timing within the planning horizon, whereas the technical constraints are respected with minimum cost [3]. Technical constraints that have to be satisfied are the following: supplying all loads, maximum allowable voltage drops at load points, maximum permissible loading of substations, network radiality, and the feeders' maximum current limits. Prevalent cost indices are substation construction cost, no-load and loading loss costs in substation transformers, and construction and network feeder loss costs.

Because of the importance of this issue, many mathematical models and algorithms have been proposed for DEP in the specialized literature [4]-[29]. In recent studies, a reference network model (RNM) has been employed for large-scale distribution planning [4]. Simultaneous planning of high-voltage (HV), medium-voltage (MV), and low-voltage (LV) networks, in addition to automatic street map generation, is one of the features of the RNM. Reference [5] introduced a balanced genetic algorithm (GA) in combination with data envelopment to solve multistage DEP. The overall performance of the proposed algorithm is studied under different uncertainties under Greenfield condition, but reliability is not modeled through the objective function. While in [6] a reliability-based approach is employed for DEP, mixed-integer linear programming (MILP) is used for the optimization process. Since the radiality constraint is guaranteed by forcing the algorithm to select only one feeding path for each load node, distributed generations (DGs) cannot be modeled through the proposed method. The multistage DEP with DG is studied in [7] using an MILP approach; although different expansion alternatives are considered, reliability is not modeled through the algorithm. A constructive heuristic algorithm is proposed for DEP in [8]; a local improvement phase and a branching technique were implemented in the solution process to improve the obtained results. This model considers all prevalent cost indices, but it is not developed for secondary distribution system planning. A simultaneous optimization of the layout and conductor type in a radial distribution network is investigated in [9]; a branch-exchange algorithm is used for layout optimization, whereas conductor optimization is solved by means of a dynamic programming algorithm. The method has been successfully tested for a large-scale network, but reliability is not considered in the proposed model. A new longterm DEP model is proposed in [10], in which urbanity uncertainties are taken into consideration. The model designates some embranchment points within the feeder routing process to eliminate harmful effects of urbanity uncertainties. In addition to these studies, several heuristic [11], [12] and metaheuristic techniques, including GA [13], EA [14], simulated annealing [15], bacterial algorithm [16], and others are investigated for DEP in the specialized literature.

Although simultaneous optimization of SEP and feeder routing is a prerequisite for optimal DEP, SEP is singly studied in some literature [17]-[27]. For example, in Iran (and some other countries), all $\mathrm{HV}$ and $\mathrm{HV} / \mathrm{MV}$ substations, in addition to transmission grids, are under the management of the regional electric companies [27]. On the other hand, distribution networks, including MV and LV feeders and distribution transformers, are under the management of distribution utilities. In this environment, SEP is investigated by the regional electric companies, and optimal feeder routing is conducted by distribution utilities using Greenfield planning [20]-[25]. Accordingly, although substation service areas, as well as their placement and sizes, are determined by the regional electric companies, final service areas and feeder routing are determined by the distribution utilities. While it is demonstrated that a branch-exchange algorithm and a Voronoi tessellation perform extremely well in achieving the optimal layout from a presumed service area [28], [29], the service areas proposed by the regional electric companies are regularly used as a yardstick to set the distribution tariffs [12], [29].

In pioneering research, [17] proposed a pseudodynamic approach to determine the sizing and timing of distribution substations. However, in the proposed algorithm, constructing new substations is completely based upon voltage drop considerations. In [18], a transportation-based methodology is applied to determine substation locations and sizes and define the associated service areas; the aim of this model is to prevent transporting power over a large distance. In [19], optimal substation locations are modeled by a fixed charge transshipment and optimized using an integer branch-and-bound technique. A heuristic algorithm is proposed in [20], in which combinational 
optimization is used to determine optimum substation capacities; then, the allocation process is conducted by minimizing a linearized model of active power losses. The proposed model does not require the selection of candidate substation locations.

In recent studies conducted on SEP, [21]-[23] have used GA in optimization process. While SEP is investigated considering uncertainty loads and load splitting in [21], [22] proposed insensitive crossover and mutation operators that somehow ensure achieving optimal or close to optimal solutions; however, solution time has been multiplied. The model considers total feeder costs, but inflation and interest rates are ignored. In [23], a binary GA is used to determine substation locations. In addition, substation service areas are defined based on loss characteristic matrix aimed at minimizing both loss and feeder length through the allocation process. A pseudodynamic nondiscrete substation planning model is proposed in [24]. In [25], mixedinteger nonlinear programming and a new long-term planning model are employed for SEP. However, since the algorithm is computationally expensive, it is not tested for a large-scale distribution system. In addition, a probabilistic methodology is presented for distribution substation locations in [26], but the method cannot determine substation capacities or service areas.

Since determining the optimal feeder areas is not an aim of SEP, feeder losses and construction costs are not considered in some literature [17]-[19], [24], [25]. On the other hand, they are modeled in some research, which shows that total costs associated with the network feeders are effective in SEP results [20]-[23].

In [17]-[27], reliability is not considered as part of the objective function; however, in [21]-[25], it is almost taken into consideration by setting a maximum permissible loading percentage for substations. On the other hand, in [30], substation capacities are determined based upon a single contingency approach, but the model does not offer any suggestion for SEP.

This paper uses a priority vector to develop a constructive heuristic algorithm for determining approximate substation service areas (ASSA) under Greenfield condition. Moreover, an enhanced EA is conducted for SEP by means of an expert initial population, a capacity-based codification, and a new selection strategy. In addition, a diversification strategy proposed in [14] is applied to the EA to avoid imprisonment of solutions in local minima. Furthermore, problem formulation is extended, and the effects of supply interruptions are added to the problem. Finally, the proposed generalized model is conducted on an actual largescale distribution system and four mathematical benchmark test systems to solve both Greenfield and static expansion problems; obtained results are presented in different scenarios to validate the effectiveness of the developed method.

The main contributions of this paper are the following:

1) a deterministic heuristic algorithm to find substation service areas;

2) a constrained initialization and a new selection strategy for the EA;

3) an enhanced EA for SEP within large distribution networks;

4) analysis of supply interruptions caused by substations' unreliability and feeder's failures on SEP results.

\section{Problem Formulation}

\section{A. Objective Function}

The aim of static SEP is to determine a set of decision variables, including substation locations and sizes and their associated service areas. These objectives must be fulfilled with minimum expansion costs while respecting technical constraints [20]-[27]. In this paper, the static SEP problem is modeled as a mixed-integer nonlinear programming problem as follows:

$$
\begin{aligned}
\text { Fit }_{\mathrm{SEP}}= & \sum_{i \in \Omega_{\mathrm{ss}}} C_{i}^{S}+\sum_{i \in \Omega_{\mathrm{ss}}} \sum_{j \in \Omega_{l}} C_{i j}^{F}\left(\rho_{k}^{j}\right) \cdot d_{i j} \cdot \beta_{i j} \\
& +\sum_{h=1}^{n_{y}} \mathrm{PW}^{h} \cdot \sum_{i \in \Omega_{\mathrm{ss}}} \sum_{j \in \Omega_{l}} \alpha \cdot \gamma \cdot \beta_{i j} \cdot C^{l} \cdot P_{i j}^{\mathrm{loss}} \\
& +\sum_{h=1}^{n_{y}} \mathrm{PW}^{h} \cdot \sum_{i \in \Omega_{\mathrm{ss}}} \sum_{j \in \Omega_{s s, i}^{\mathrm{tr}}} \alpha \cdot C^{l} \\
& \cdot\left[P_{i j}^{\mathrm{iron}}+P_{i j}^{\mathrm{cu}} \cdot \gamma \cdot\left(\frac{S_{i}^{S}}{C S_{i}}\right)^{2}\right] \\
& +\sum_{h=1}^{n_{y}} \mathrm{PW}^{h} \cdot \sum_{i \in \Omega_{\mathrm{ss}}} \sum_{j \in \Omega_{l}} \alpha \cdot \kappa \\
& \cdot\left[\left(\frac{\lambda_{i j} \cdot \tau_{i j} \cdot d_{i j}}{\alpha}\right)\left(\frac{u_{i}^{s}}{\alpha}\right)\right] \cdot \beta_{i j} \cdot C^{S I} \cdot S_{j}^{l}
\end{aligned}
$$

where

$$
d_{i j}=\xi_{d} \cdot\left[\left|x_{i}-x_{j}\right|+\left|y_{i}-y_{j}\right|\right] \quad \forall i \in \Omega_{\mathrm{ss}}, \quad \forall j \in \Omega_{l}
$$

$$
\mathrm{PW}=\frac{1+\mathrm{Infr}}{1+\mathrm{Intr}}
$$

$P_{i j}^{\text {loss }}=\frac{\left(S_{j}^{l}\right)^{2} \cdot d_{i j} \cdot r_{i j}}{\left|V_{n}\right|^{2}} \quad \forall i \in \Omega_{\mathrm{ss}}, \quad \forall j \in \Omega_{l}$

$$
S_{i}^{S}=\sum_{j \in \Omega_{l}} \beta_{i j} \cdot\left(S_{j}^{l}+P_{i j}^{\text {loss }}\right) \quad \forall i \in \Omega_{\mathrm{ss}} .
$$

The objective function of the SEP problem is represented in (1), where the first term shows expansion (or construction) costs of the selected substations within the planning horizon [8]. While the expansion cost of a typical existing substation is dependent on the sizes of new transformers, the construction cost of a typical new substation is associated with land costs, sizes of selected transformers, protective equipment, etc.

Total required costs for expanding MV feeders are considered in the second term of (1) [20]-[23]. In this term, $C_{i j}^{F}\left(\rho_{k}^{j}\right)$ is a variable and indicates the total construction/reinforcement cost of a feeder located between nodes $i$ and $j$ by conductor $\rho_{k}$ [22]. It should be noted that, in this paper, the conductor selection method is investigated based on a simple procedure proposed in [10] and [29]. In addition, $d_{i j}$ in (1) shows the length of a feeder located between nodes $i$ and $j$. As can be seen in the second term, it is assumed that each load point is straightly supplied by a distribution substation. Although this 
approach is not practically accurate, since optimal feeder routing is not an aim of SEP, it facilitates planning considerations and is usually used in specialized literature on the SEP problem [19]-[26]. Since the load concentration point is a dummy point, finding its path along the streets is impossible [10]. Meanwhile, determination of the distance by radial and direct method is not advisable because covering such a distance is practically unlikely [13]. Hence, in this paper, a distance determination with good practical results is considered as (2), in which a distance correction factor, i.e., $\xi_{d}$, is used to properly model the actual feeder constructed within each corridor [13], [22].

The third term of (1) represents total costs associated with medium feeder losses, in which $\gamma$ indicates the load loss factor and is calculated as the ratio of the average load loss to the peak load loss; thus, the third term shows the overall average energy lost within network feeders. In this term, $P_{i j}^{\text {loss }}$ indicates the power losses of a feeder located between nodes $i$ and $j$ and calculates through (4) [12], [19]-[23]. In (4), $r_{i j}$ is the resistance per length of feeder $i-j$, which is dependent on the selected conductor. Since the payments of losses are in the future, they should be discounted or enhanced to reflect the time value of money [31]. To do so, effects of yearly interaction and interest rates are considered in a present worth factor as (3) and applied to the third term of (1) [24], [25].

The imposed costs due to the power losses within substations are modeled through the fourth term of (1); while the first phrase shows substations' no-load loss costs, substations' loading loss costs are considered in the second phrase, which illustrates that the $\mathrm{Cu}$ loss of a substation is proportional to the square of transformer's loading [9]-[11], [20]-[25]. In this term, $S_{i}^{S}$ represents the total power provided by substation $i$, which is dependent on its associated service areas and calculates through (5) [12].

Finally, the total cost of supply interruption due to failures within network feeders and substations is taken into account in the last term of (1) [6], [10]. In this term, while $\lambda_{i j} \cdot \tau_{i j} \cdot d_{i j} / \alpha$ represents the probability of supply interruption in load point $j$ due to failures within network feeders, effects of substation outage times on the probability of supply interruption are considered by $u_{i}^{s} / \alpha$. Since the mentioned events are independent, the union of probabilities provides the total probability of supply interruption of each load point [32].

\section{B. Problem Constraints}

The prevalent constraints governing the SEP problem are as follows.

1) Radiality Constraint

The distribution network should be made up of a radial structure based on an operational viewpoint [7]-[15]. Since optimal feeder routing is not an aim of SEP, the radiality constraint is simply achieved by this assumption that all load points should only be supplied through one substation through the planning period [19]-[25]. This constraint is guaranteed by

$$
\sum_{i \in \Omega_{\mathrm{ss}}} \beta_{i j}=1 \quad \forall j \in \Omega_{l} .
$$

2) Maximum Permissible Loading of Substations

Considering the technical requirements, substation loading must fall within an acceptable margin. Substation transformers' thermal limits, transmission line restrictions, and regional subsynchronous resonance are some of these technical constraints [33], [34]. In addition, due to reliability considerations, substations should have less loading than their nominal capacity [35]. These requirements are mathematically expressed by

$$
\psi^{\min } \cdot C S_{i} \leq S_{i}^{S} \leq \psi^{\max } \cdot C S_{i} \quad \forall i \in \Omega_{\mathrm{ss}} .
$$

\section{3) Voltage Drop}

Distribution utilities are obliged to meet customers' load demand within the standard power quality requirements. Given that distribution substations play an important role in the distribution network layout, they should provide the basic technical context for downstream feeders. Accordingly, the entire load points must supply within maximum permissible voltage drops as presented in (8) [12], [20]-[26]. It should be noted that all distribution substations have the same voltage level equal to the nominal value $\left(V_{n}\right)$ [36], i.e.,

$$
\left|\frac{S_{j}^{l} \cdot \sum_{k \in \Omega_{\mathrm{ss}}}\left[\beta_{k j} \cdot d_{k j} \cdot z_{k j}\right]}{V_{n}}\right| \leq \Delta V_{\max } \quad \forall j \in \Omega_{l} .
$$

4) Thermal Capacity of the Feeders

Every feeder has a thermal capacity limit set by the maximum current, which it can carry through its conductor [2]. This constraint is met by [22]

$$
\frac{S_{j}^{l}}{V_{n}} \leq I_{\rho_{k}^{j}}^{\max } \quad \forall j \in \Omega_{l} .
$$

\section{ASSA}

While substation locations and sizes are known (Greenfield condition), the aim of SEP is to allocate load points among substations so that proper electrical supply to consumers can be achieved with minimum cost. According to mathematics theory, a globally optimal solution is accessible for any optimization problem by utilizing a thorough search through the problem search space [37]. Given the combinatorics theory, the number of ways that any one of $k$ values can be assigned to each of $n$ items is $k^{n}$ [38]. Hence, the total search space for defining substation service areas of a network, which have $n_{l}$ load points and $n_{s}$ substations, is $\left(n_{s}\right)^{n_{l}}$. Clearly, the direct search method is almost useless in most cases due to its high computational burden.

Here, a constructive heuristic algorithm is presented to find the ASSA. The proposed solution of this method is applied to generate expert initial population and a new selection strategy for the SEP EA. At any iteration of the proposed ASSA algorithm, the priority value of connecting any of the loads to the substations is calculated. Then, the most proper load point is selected and supplied by its most suitable substation. Afterward, the same process is repeated until the entire load 
points are allocated. In order to find "the most proper load point" and "its most suitable substation" at each instant, such as $t$, the following procedure is carried out. First, a set of unsupplied load points, i.e., $\Omega_{l, t}^{\text {un }}$, and a set of selectable substations associated to each of the unsupplied load points is determined, i.e., $\Omega_{i, t}^{s}$. It is assumed that the $j$ th substation is a member of the set $\Omega_{i, t}^{s}$ if supplying load point $i$ from substation $j$ at instant $t$ does not violate SEP constraints represented in (6)-(8). Then, the total cost of supplying load points from each substation is calculated using

$$
\begin{aligned}
C_{i j, t}^{\mathrm{sup}}= & C_{i j}^{F}\left(\rho_{k}^{j}\right) \cdot d_{i j}+\sum_{h=1}^{n_{y}} \mathrm{PW}^{h} \cdot \alpha \cdot \gamma \cdot C^{l} \cdot P_{i j}^{\text {loss }} \\
& +\sum_{h=1}^{n_{y}} \mathrm{PW}^{h} \cdot \sum_{k \in \Omega_{s s, i}^{\mathrm{tr}}} \alpha \cdot \gamma \cdot C^{l} \cdot P_{i k}^{\mathrm{cu}} \cdot\left(\frac{S_{j}^{l}}{C S_{i}}\right)^{2} \\
& +\sum_{h=1}^{n_{y}} \mathrm{PW}^{h} \cdot \alpha \cdot \kappa \cdot\left[\left(\frac{\lambda_{i j} \cdot \tau_{i j} \cdot d_{i j}}{\alpha}\right) \cup\left(\frac{u_{i}^{s}}{\alpha}\right)\right] \\
& \cdot C^{S I} \cdot S_{j}^{l} .
\end{aligned}
$$

All the terms of (10) are precisely described in Section II. By sorting these costs in ascending order, the most suitable substations for any load point and their associated costs are determined as follows:

$$
\begin{aligned}
& \Omega_{l, i t}^{\mathrm{sup}}=\{\underbrace{C_{i j, t}^{\mathrm{sup}}}_{C_{i 1, t}}, \underbrace{C_{i k, t}^{\mathrm{sup}}}_{C_{i 2, t}}, \ldots, \underbrace{C_{i m, t}^{\mathrm{sup}}}_{C_{i\left(\left|\Omega_{i t}^{\mathrm{sub}}\right|\right), t}}\} \\
& C_{i j, t}=\Omega_{l, i t}^{\mathrm{sup}}(1, j) \quad \forall i \in \Omega_{l, t}^{\mathrm{un}}, j \in \Omega_{i t}^{\mathrm{sub}}
\end{aligned}
$$

where $C_{i j, t}$ represents the cost of supplying load point $i$ from the $j$ th suitable substation at $t$ th iteration. According to the preceding equations, it is evident that the substation associated to the $j$ th element of $\Omega_{l, i t}^{\text {sup }}$ is the $j$ th suitable substation for supplying load point $i$ at instant $t$ from the cost point of view with respect to the technical constraints of (6)-(8). This means that while substation capacities are infinite, minimum expansion costs would be achieved by supplying each load point from its most suitable substation. However, once the maximum permissible loading of substations is considered, load points should be allocated according to their priority. For example, as a greedy algorithm, it can be assumed that, at each instant $t$, a load point corresponds to the minimum amount of (10) to be supplied by its suitable substation. In order to find an enhanced pseudodynamic deterministic algorithm, an approximate value vector and a priority value are defined.

The approximate value vector shows the approximate worth of supplying load point $i$ from the $j$ th suitable substation in an iteration. This is a vector of dimension $\left|\Omega_{l, t}^{u n}\right|$; the elements of its rows are calculated by the absolute value of the difference in cost resulting from supplying load point $i$ from the $j$ th and $(j+1)$ th suitable substations, as shown in

$$
\omega_{i j, t}=\left|C_{i j, t}-C_{i(j+1), t}\right| \quad \forall j,(j+1) \in \Omega_{i t}^{\mathrm{sub}} .
$$

In the preceding equation, $\omega_{i j}$ indicates the incremental cost that would be imposed on the system if load point $i$ is supplied from its $(j+1)$ th suitable substation instead of the $j$ th substation. Thus, minimizing this incremental cost might be used as a new approach for the load allocation problem. It should be noted that the priority value of supplying a load point from its most suitable substation is dependent on the status of the selectable substations and the status of other load points. While the approximate value of each substation is calculated through (13), the priority value of each load point rather than the other ones can be determined by combining these values, as presented in

$$
\begin{array}{r}
\mathrm{PV}_{i}^{t}=\sum_{j=1}^{\left|\Omega_{i t}^{s}\right|} 10^{-[\sigma \times(j-1)]} \cdot\left[\frac{\omega_{i j, t}}{\left(\sum_{k \in \Omega_{l, t}^{\text {un }}} \omega_{k j, t}\right)+\varepsilon}\right] \\
\forall i \in \Omega_{l, t}^{\mathrm{un}}, \sigma>0 .
\end{array}
$$

In this equation, $\omega_{i j, t} / \sum_{k \in \Omega_{l, t}^{\text {un }}} \omega_{k j, t}$ is used to normalize $\omega_{i j, t}$ at any iteration; with this action, the approximate value vector of each load point is weighted according to the approximate value vectors of the entire load points. In addition, $\varepsilon$ (a very small number) is added to (14) in order to make sure that $\mathrm{PV}_{i}^{t}$ amounts to a certain number, particularly when $\omega_{i j, t}$ is equal to 0 for all load points. The gain $10^{-[\sigma \times(j-1)]}$ is a penalty parameter that reduces the effects of the less suitable substations rather than the most suitable ones in any iteration. Once $j=1$, i.e., the most suitable substation for each load point, $10^{-[\sigma \times(j-1)]}$ is equal to 1 , and the normalized $\omega_{i j, t}$ is not changed. For the next suitable substations, $j>1$; thus, $10^{-[\sigma \times(j-1)]}<1$, which is less than that of the most suitable substation. According to (1), as the priority of a substation decreases, the amount of $j$ increases, which leads to a further decrease in $10^{-[\sigma \times(j-1)]}$. Hence, this gain can adequately reduce the effects of less suitable substations rather than the most suitable ones in any iteration; this is the motivation behind incorporating the mentioned gain. For example, when two or more load points have the same amount of $\omega_{i 1, t}$, this parameter helps the algorithm achieve the best solution relating to the value of other substations. In this gain, $\sigma$ is an impact factor and can be initialized by the user. As $\sigma$ increases, the effects of less suitable substations on priority value decreases. It is empirically seen in simulations that, if $\sigma \geq 3$, the ASSA algorithm can achieve proper solutions when a number of load points have the same amount of $\omega_{i 1, t}$; in this paper, $\sigma$ is set equal to 3 .

In each iteration, the load point that corresponds to the largest priority value [see (14)] is selected and supplied by its most suitable substation. Then, the steps described are repeated until all load points are allocated.

The overall process of the proposed ASSA algorithm is as follows.

Step 1) Technical and economic information is received.

Step 2) Set of unsupplied load points is found, i.e., $\Omega_{l, t}^{\text {un }}$.

Step 3) Selectable substations are determined for each unsupplied load point $\Omega_{i t}^{s}$ with respect to (6)-(8). 


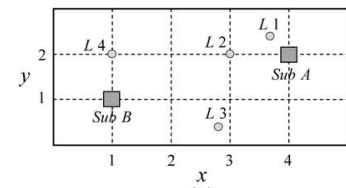

(a)

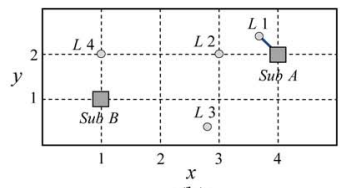

(b)

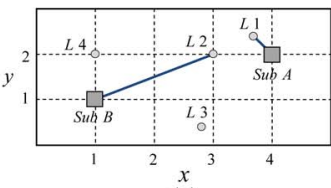

(c)

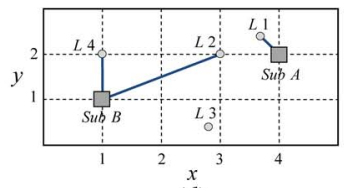

(d)

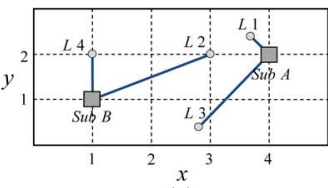

(e)

Fig. 1. Illustrative example for the proposed ASSA algorithm. (a) Test system. (b)-(e) Results of each iteration of the ASSA algorithm.

TABLE I

Obtained Results of THE Proposed ASSA Algorithm For THE ILlustrative EXAMPLE IN Fig. $1\left(C_{i j}^{\text {sup }} \cong S_{i} \cdot d_{i j}\right)$

\begin{tabular}{|c|c|c|c|c|c|}
\hline \multicolumn{2}{|r|}{ Load \# } & $L 1$ & $L 2$ & $L 3$ & $L 4$ \\
\hline \multicolumn{2}{|c|}{ Demand (MVA) } & 9 & 10 & 5 & 8 \\
\hline \multirow{5}{*}{$\begin{array}{l}\text { First } \\
\text { Iteration }\end{array}$} & $C_{(L i) A, 1}^{\text {sup }}$ & 4.5 & 15 & 9 & 24 \\
\hline & $C_{(L i) B, 1}^{S u p}$ & 26.1 & 18 & 9 & 8 \\
\hline & $P V_{(L i)}^{1}$ & 0.532 & 0.074 & 0 & 0.394 \\
\hline & $\begin{array}{c}\text { The most suitable } \\
\text { substation }\end{array}$ & $A$ & $A$ & $A($ or $B)$ & $B$ \\
\hline & Result & \multicolumn{4}{|c|}{$L 1$ is connected to sub $A, \operatorname{sub} A$ has 6 MVA free capacity. } \\
\hline \multirow{5}{*}{$\begin{array}{l}\text { Second } \\
\text { Iteration }\end{array}$} & $\overline{C_{(L i) A, 2}^{\text {sup }}}$ & \multirow{4}{*}{$\begin{array}{l}L 1 \text { has } \\
\text { already } \\
\text { serviced }\end{array}$} & 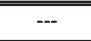 & 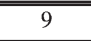 & 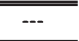 \\
\hline & $C_{(L i) B, 2}^{\text {sup }}$ & & 18 & 9 & 8 \\
\hline & $P V_{(L i)}^{2}$ & & 0.692 & 0 & 0.307 \\
\hline & $\begin{array}{c}\text { The most suitable } \\
\text { substation }\end{array}$ & & $B$ & $A($ or $B)$ & $B$ \\
\hline & Result & \multicolumn{4}{|c|}{$L 2$ is connected to sub $B, \operatorname{sub} B$ has 15 MVA free capacity. } \\
\hline \multirow{5}{*}{$\begin{array}{l}\text { Third } \\
\text { Iteration }\end{array}$} & $C_{(L i) A, 3}^{\text {sup }}$ & \multirow{4}{*}{$\begin{array}{l}L 1 \text { has } \\
\text { already } \\
\text { serviced }\end{array}$} & \multirow{4}{*}{$\begin{array}{c}L 2 \text { has } \\
\text { already } \\
\text { serviced }\end{array}$} & 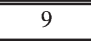 & 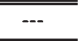 \\
\hline & $C_{(L i) B, 3}^{\text {sup }}$ & & & 9 & 8 \\
\hline & $P V_{(L i)}^{3}$ & & & 0 & 1 \\
\hline & $\begin{array}{l}\text { The most suitable } \\
\text { substation }\end{array}$ & & & $A($ or $B)$ & $B$ \\
\hline & Result & \multicolumn{4}{|c|}{$L 4$ is connected to $\operatorname{sub} B, \operatorname{sub} B$ has 7 MVA free capacity. } \\
\hline $\begin{array}{l}\text { Fourth } \\
\text { Iteration }\end{array}$ & Result & \multicolumn{4}{|c|}{$\begin{array}{l}L 3 \text { is connected to sub } A, \operatorname{sub} A \text { has } 1 \text { MVA free capacity. } \\
\text { (or } L 3 \text { is connected to sub } B, \operatorname{sub} B \text { has } 2 \text { MVA free capacity) }\end{array}$} \\
\hline
\end{tabular}

Step 4) Set of suitable substations for the unsupplied load points $\left.\Omega_{l, i t}^{\text {sup }}\right)$ is calculated using (10)-(12).

Step 5) Equation (14) is calculated for the entire unsupplied load points.

Step 6) Load point that corresponds to the largest element of (14) is connected to its appropriate substation.

Step 7) Steps 2-6 are repeated until all load points are allocated.

A simple system with four load points and two substations is depicted in Fig. 1. It is assumed that substations $A$ and $B$ have capacities of 15 and 25 MVA, respectively. Complete system data and obtained results of the ASSA iterations are presented in Table I. As shown in this table, in the first iteration, $L 1$ is the load point whose connection to the second most suitable substation $(B)$ instead of the most suitable one $(A)$ imposes maximal cost to the system (0.532). Thus, it is selected and supplied by its appropriate substation $(A)$. Afterward, substations' free capacities are updated, and selectable substations for the unallocated load points are determined. As can be seen in the second iteration, since substation $A$ does not have free capacity, $L 2$ and $L 4$ cannot be supplied through $A$; thus, substation $A$ is not a member of the sets $\Omega_{(L 2) 2}^{s}$ and $\Omega_{(L 3) 3}^{s}$. Since it makes no difference if $L 3$ is supplied from substation $A$ or $B$, its priority value is equal to 0 . According to Table $\mathrm{I}$, the program is terminated in four iterations, i.e., when the entire load points are allocated. It should be noted that the proposed ASSA algorithm has almost a linear time complexity, which makes it desirable within large-scale networks, particularly in comparison with the EAs [39].

\section{SOLUTION APPROACH}

In this paper, the optimization procedure is conducted using an enhanced EA. The EA is a mathematical model inspired by nature, which uses some mechanisms based on evolution and natural genetic operators. These operators are hired, aiming at finding the optimal solution by purposive search through the problem search space [14]. Such algorithms employ a population (chromosomes) of individuals, which undergo selection in the presence of variation, including operators of mutation and crossover. In each generation, the fitness function is evaluated, and a new population is formed. The algorithm is terminated when either a maximal number of iterations have been produced or a satisfactory fitness level has been reached [40].

In this paper, a new capacity-based codification is presented for the SEP, as presented in

$$
\begin{aligned}
\vartheta_{i} & =[\boldsymbol{V}, \boldsymbol{W}]=[\underbrace{v_{1}, v_{2}, \ldots, v_{\left|\Omega_{s}\right|} \mid}_{\text {Sizing }} \underbrace{w_{1}, w_{2}, \ldots, w_{\left|\Omega_{l}\right|}}_{\text {Service Areas }}] \\
v_{i} & =\left\{0,1, \ldots, \mid \Omega_{s, i}^{\mathrm{tr} \mid}\right\} \quad \forall i=1, \ldots,\left|\Omega_{s}\right| \\
w_{i} & =\left\{1,2, \ldots,\left|\Omega_{s}\right|\right\} \quad \forall i=1, \ldots,\left|\Omega_{l}\right| \\
\beta_{i j} & =\left\{\begin{array}{ll}
1, & w_{j}=i \\
0, & w_{j} \neq i
\end{array} \quad \forall i \in \Omega_{s}, j \in \Omega_{l} .\right.
\end{aligned}
$$

In the preceding equations, $\boldsymbol{V}$ represents the substations' capacity vector, where $v_{i}$ is a gene that shows the capacity of substation $i$ at the planning horizon. According to (16), if $v_{i}=0$, the $i$ th substation is not selected. In addition, $\boldsymbol{W}$ is the substations' service area vector so that $w_{j}$ shows which substation must supply load point $j$ through the planning horizon. Once vector $\boldsymbol{W}$ is initialized, it can be easily decoded by (18). According to this equation, if $w_{j}=i$, the binary decision variable $\beta_{i j}$, which shows that substation $i$ supplies load point $j$, is set equal to 1 and 0 otherwise. It should be noted that each load point is a representative of an electrical domain, which consists of several customers. Hence, geographical characteristics and the power demand of these load points should be calculated for a real-life distribution network. To do so, the following relations are employed [26]:

$$
\begin{aligned}
S_{i}^{l} & =\sum_{j \in \Omega_{i}^{\mathrm{ED}}} S_{j} \quad \forall i \in \Omega_{l} \\
x_{i} & =\frac{\sum_{j \in \Omega_{i}^{\mathrm{ED}}} S_{j} \cdot x_{j}}{\sum_{j \in \Omega_{i}^{\mathrm{ED}}} S_{j}} \quad \forall i \in \Omega_{l} \\
y_{i} & =\frac{\sum_{j \in \Omega_{i}^{\mathrm{ED}}} S_{j} \cdot y_{j}}{\sum_{j \in \Omega_{i}^{\mathrm{ED}}} S_{j}} \quad \forall i \in \Omega_{l} .
\end{aligned}
$$


In the preceding equations, $\Omega_{i}^{\mathrm{ED}}$ represents the set of customers in the $i$ th electrical domain, and $S_{j}$ indicates load consumption of the $j$ th customer in this domain. It is evident that any other methodology may be used to define representatives of each electrical domain, without loss of generality.

It is important to note that, although the chromosome structure introduced in [21]-[23] presents the total capacity of each substation, no proposal is put forward about which set of transformers should be installed in the substation so that the selected capacity is achieved. Therefore, the optimal solution may not be achieved when a combination of transformers can be installed within each substation. Hence, the proposed codification is useful for reliability evaluation of substations since it facilitates the calculation of the capacity outage probability table of substations [32].

While a part of the initial population is generated by random numbers, the remaining chromosomes are produced by an expert generation strategy. To do so, first, a set of random numbers is generated for vector $\boldsymbol{V}$; this action produces a set of substation locations and sizes. Then, by means of the proposed ASSA algorithm, substation service areas $(\boldsymbol{W})$ are calculated for any vector $\boldsymbol{V}$. Finally, they are combined to form the proposal chromosomes.

While the initial population is generated, the fitness function is evaluated for each individual population. Then, a set of the best population is separated for the crossover and mutation process using a selection strategy. In this paper, a set of nonelite population $\left[\left(1-k_{\mathrm{sel}} \%\right) \cdot n_{\mathrm{pop}}\right]$ is separated from the initial population [14]. Afterward, the second part of each chromosome $(\boldsymbol{W})$ is changed by means of the proposed ASSA algorithm, and the tournament technique is used to select the best configurations between new chromosomes and the previous ones. Moreover, a diversification strategy proposed in [14] is used to avoid strong attraction to local minima caused by the selection mechanism of the EA. Then, crossover and mutation operators are separately applied to each part of the selected chromosomes $(\boldsymbol{V}, \boldsymbol{W})$ to generate the new population. It should be noted that since $v_{i}$ and $w_{i}$ are set according to (16) and (17), respectively, the GA operators should separately be conducted on $\boldsymbol{V}$ and $\boldsymbol{W}$ to limit generating infeasible solutions. The mentioned steps are repeated until the EA termination condition is achieved.

\section{Tests And Results}

Aimed at solving the SEP problem by the proposed method, software is developed in a MATLAB environment. By providing the geographic-information-system-ready map and entering technical and economic information, the user can see the SEP results. In this paper, the SEP (see Fig. 2) is solved for the city of Hamedan, the center of Hamedan province in Iran [41].

The Hamedan Electrical Distribution Company had 419009 consumers in 2008, of which 140379 were in the urban areas of Hamedan. The aim is to solve the long-term static SEP for the urban area of Hamedan in 2014. The planning zone and the approximate electrical energy consumption of Hamedan within the planning horizon are shown in Figs. 3 and 4 , respectively. Interest and inflation rates are set equal to

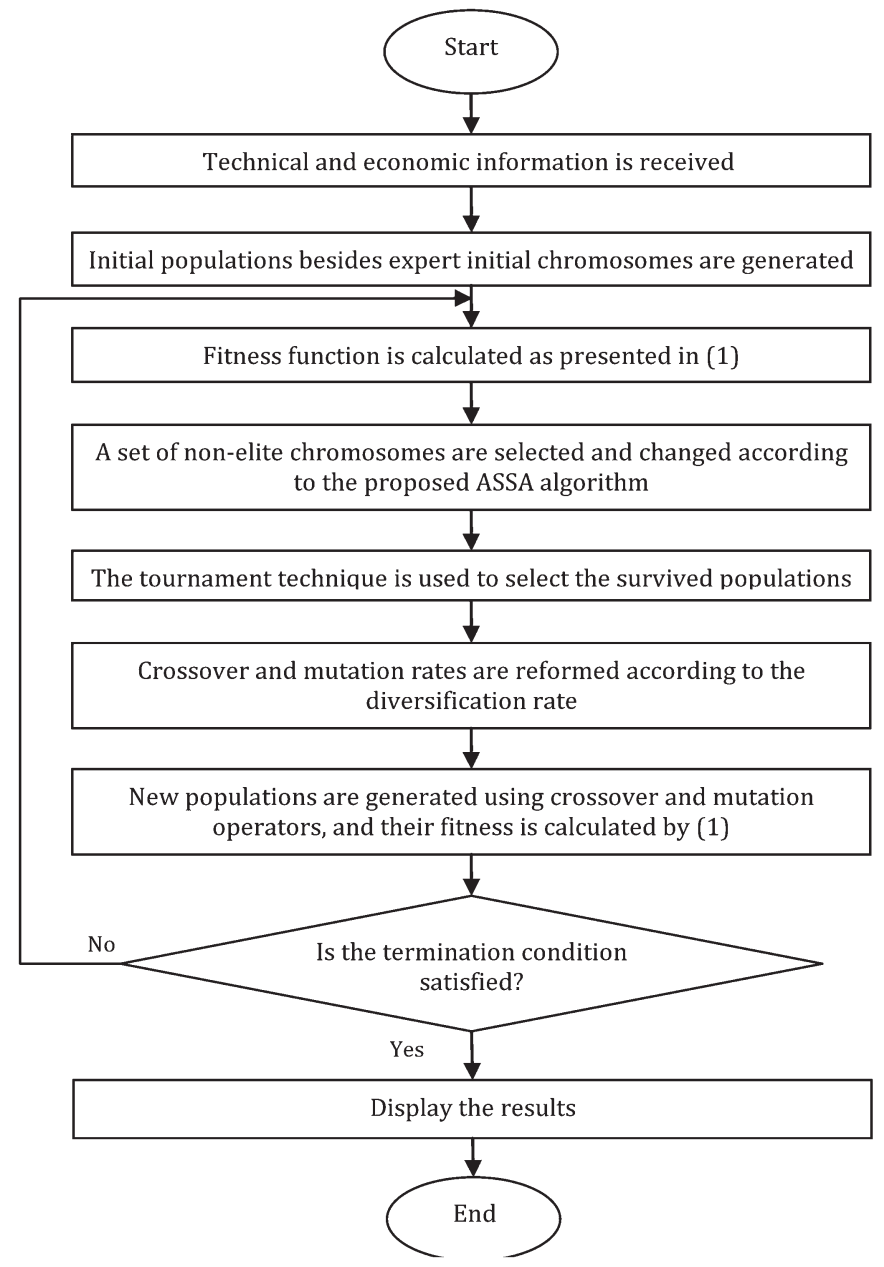

Fig. 2. Overall process of the proposed SEP algorithm.

$10 \%$ and $8 \%$, respectively. The maximal permissible loading percentage for all substations, the maximal permissible voltage drop, and the planning horizon are assumed equal to $75 \%$, $5 \%$, and 6 years, respectively. Loss factor and load factor for the entire load points, cost of energy losses, cost of supply interruption, failure rate, and average repair time of feeders are set equal to $\$ 0.36 / \mathrm{kWh}, \$ 0.56 / \mathrm{kWh}$, and $\$ 0.07 / \mathrm{kWh} ; \$ 2 / \mathrm{kWh}$; 0.1 failure per kilometer per year; and $3 \mathrm{~h}$, respectively. In addition, the conductor selection method is investigated based on [10] and [29], and installable conductors are assumed according to [42]. Costs and outage times of typical $63-/ 20-\mathrm{kV}$ substations are shown in Table II. According to the capacity outage probability table, the total outage time of a substation with multiple transformers is less than a substation with a unique transformer [32]. Hence, in this paper, total outage time of a substation is calculated by dividing the average outage times of its transformers by the total number of the substation's installed transformers. For example, the total outage time of a substation with two 15-MVA transformers is assumed equal to $6.5 \mathrm{~h}$ since $1 / 2 \times((13+13) / 2)=6.5$. It is obvious that any other methodology may be used to define total outage time of a substation without loss of generality. A complete data listing of the planning zone can be found in the supplementary data of this paper [44]. Moreover, technical specifications of the computer used for simulations are 


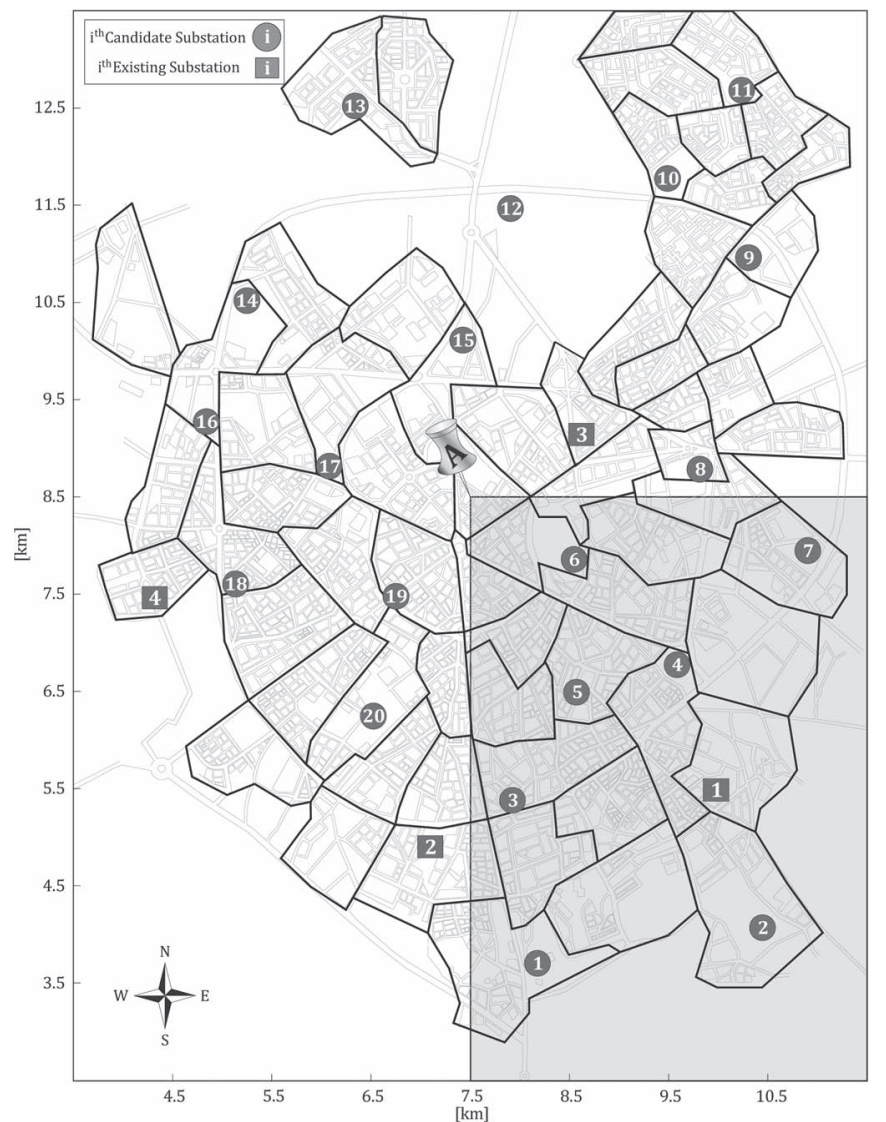

Fig. 3. Planning zone, i.e., city of Hamedan, Iran.

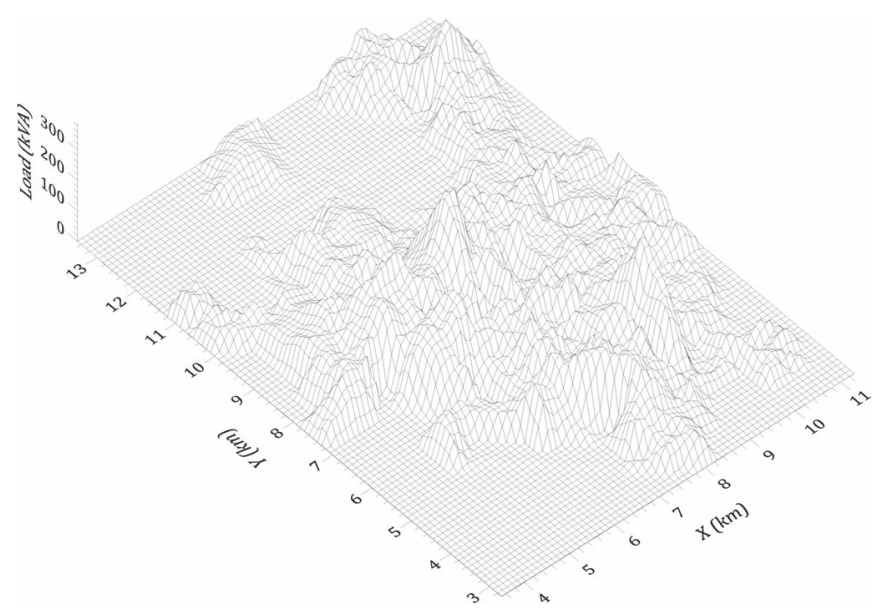

Fig. 4. Approximate electrical energy consumption of the planning zone.

TABLE II

CAPACITY AND COST OF TYPICAL 63-/20-kV TRANSFORMERS AND RELATED EQUiPMENT USES WITHIN IRANIAN DisTRIBUTION NETWORKS

\begin{tabular}{c|c|c|c|c|c|c}
\hline Size (MVA) & 15 & 30 & 45 & 60 & 75 & 90 \\
\hline Cost (million \$) & 0.370 & 0.632 & 0.825 & 1.050 & 1.237 & 1.485 \\
\hline Outage time (h/year) & 1.3 & 1.0 & 1.2 & 1.5 & 1.7 & 2.0 \\
\hline
\end{tabular}

Centrino1.8-GHz central processing unit with $1 \mathrm{~GB}$ of random access memory.

Here, the main contributions of this paper are numerically studied in three scenarios. The first scenario investigates the capabilities of the proposed ASSA method rather than an EA.

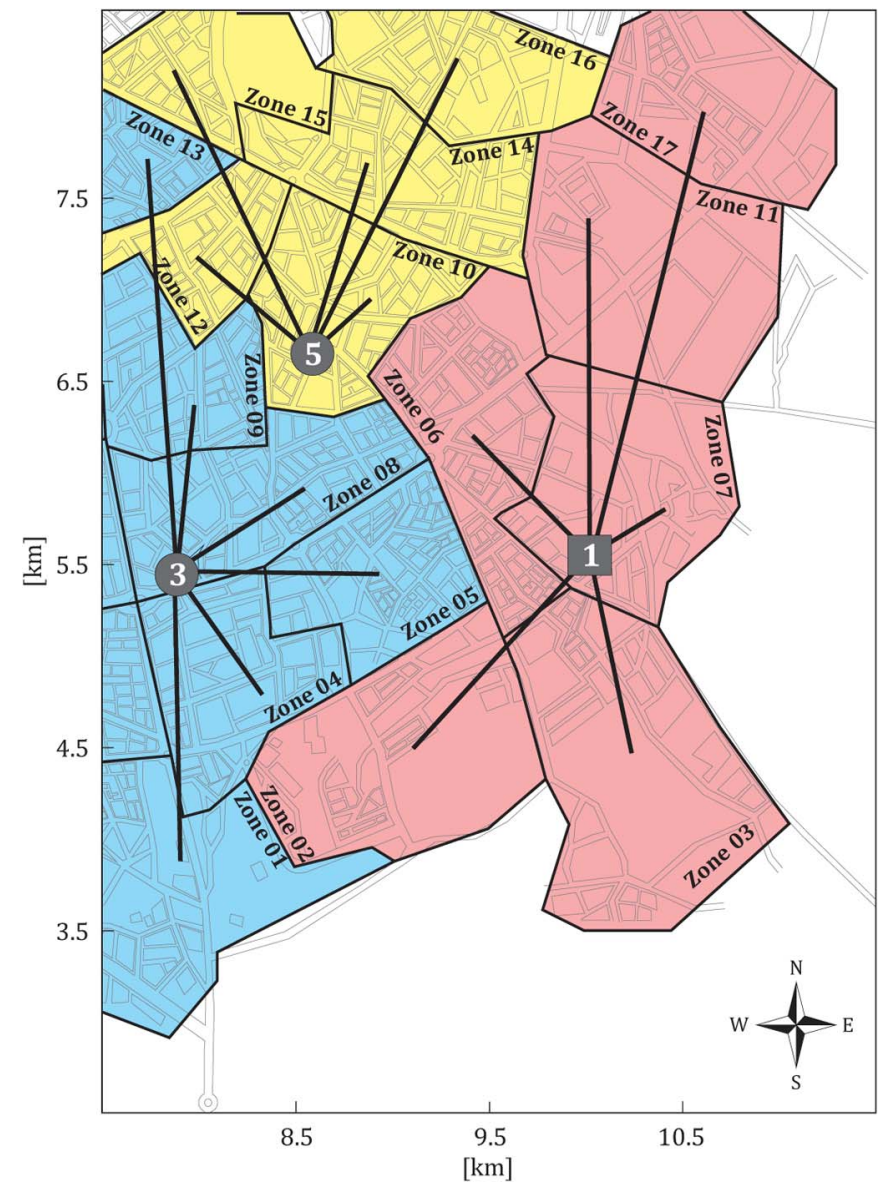

Fig. 5. Proposed ASSA solution for block $A$ in Fig. 3.

To do this, obtained results of the ASSA algorithm, in addition to those of the GA, are reported for four benchmark test systems and a real-life distribution network, and the results are discussed. The purpose of the second scenario is to illustrate the performance of the proposed SEP method within an actual large-scale distribution system. In addition, sensitivity analysis is carried out to investigate potencies of the enhanced SEP method for several network sizes. Finally, in the third scenario, the effects of the formulated reliability model of (1) on SEP results are examined. Moreover, intensive sensitivity analysis is carried out to illustrate the efficacy of the proposed EA parameters, namely, rate of expert initial population (ROEIP) and rate of expert selection, i.e., $k_{\text {sel }}$.

\section{A. First Scenario}

In this scenario, the proposed ASSA algorithm is used to find the optimal substation service areas for four benchmark test systems presented in [43] and [44] and block $A$ in Fig. 3, shown in detail in Fig. 5. Moreover, a simple GA, which was reinforced by mutation and single-point crossover, is conducted for ten independent runs, and results obtained are compared with those of the ASSA algorithm.

Although there are several test systems for DEP, to the best of our knowledge, there is no available benchmark test system for the SEP problem [19]-[25]. Hence, the test systems under study were originally developed for the multidimensional knapsack 
TABLE III

Comparison Between Results of DifFerent Methods For Benchmark Test Systems PResented in [43] And [44] $\left(\left|\Omega_{s}\right|=25\right)$

\begin{tabular}{c|c|c|c|c|c}
\hline $\begin{array}{c}\text { \# of load points } \\
\text { (problem code) }\end{array}$ & $\begin{array}{c}\text { Solution } \\
\text { method }\end{array}$ & $\begin{array}{c}\text { Best } \\
\text { solution }\end{array}$ & $\begin{array}{c}\text { Ave. of } \\
\text { solutions }\end{array}$ & $\begin{array}{c}\text { Standard } \\
\text { deviation }\end{array}$ & $\begin{array}{c}\text { Ave. time } \\
\text { (sec) }\end{array}$ \\
\hline $\begin{array}{c}100 \\
\text { (MK_gk02) }\end{array}$ & ASSA & 752 & 752 & 0 & 0.17 \\
\cline { 2 - 6 } & GA & 766 & 769.1 & 1.868 & 232.38 \\
\hline \hline $\begin{array}{c}150 \\
\text { (MK_gk03) }\end{array}$ & ASSA & 1074 & 1074 & 0 & 0.39 \\
\cline { 2 - 6 } & GA & 1105 & 1112.5 & 3.721 & 289.12 \\
\hline \hline $\begin{array}{c}200 \\
\text { (MK_gk05) }\end{array}$ & ASSA & 1433 & 1433 & 0 & 0.72 \\
\cline { 2 - 6 } & GA & 1492 & 1509.6 & 9.676 & 340.56 \\
\hline \hline \multirow{5}{500}{} & ASSA & 3641 & 3641 & 0 & 5.17 \\
\cline { 2 - 6 } (MK_gk07) & GA & 3987 & 4196.6 & 136.262 & 1085.65 \\
\hline
\end{tabular}

TABLE IV

Results of the Proposed ASSA Algorithm for Block $A$ IN Fig. 3

\begin{tabular}{cccc}
\hline No & Capacity (MVA) & Load (MVA) & Loading (\%) \\
\hline Existing 01 & 30 & 18.44 & 61.48 \\
\hline Candidate 03 & 30 & 11.06 & 36.88 \\
\hline Candidate 05 & 15 & 8.53 & 56.87 \\
\hline
\end{tabular}

problem, in which the aim is to find a subset of items that yields a maximum profit without exceeding resource capacities [45]. Accordingly, in order to investigate the performance of the proposed ASSA algorithm, dimensions of the knapsack and items are assumed as substations and load points, respectively. Moreover, the expected power demand of load points is set equal to the items' profit. The problem is conducted to minimize the total cost of the allocation process.

Obtained results of the four benchmark test systems are presented in Table III. As shown, in the second row of this table, the first test system consisted of 100 load points and 25 substations; the proposed ASSA algorithm achieved a better solution than the GA (1.8\%) and substantially decreased the solution time (99.9\%). In the last test system, which consists of 500 load points, the ASSA algorithm could improve the GA solution by $8.6 \%$, which illustrates the usefulness of the proposed method for large-scale systems. In addition, the fifth column of the table shows that the standard deviation of the ASSA algorithm is equal to zero. The main reason for this property is that the proposed ASSA method is a deterministic heuristic algorithm, in which obtained results of each step do not change during several independent runs. In fact, the methodology [see (10)-(14)], which is employed to find the most proper load point and its most suitable substation, leads to a unique solution at each iteration of the ASSA algorithm. Considering these observations, although the proposed ASSA method may not lead to the global optimal solution, it can guarantee achieving a unique proper solution with low computational burden within each independent run. Furthermore, once the ASSA method is integrated with an EA, it can increase the convergence chance to a global optimal solution.

Block $A$ in Fig. 3 is a district that contains 17 electrical domains, in which three substations are assumed to be in Greenfield condition according to the first and second columns in Table IV ( $\psi^{\max }=0.75$ for all substations). The proposed ASSA algorithm and GA are separately used to find the optimal substation service areas. Obtained results are shown in Fig. 5 and Tables IV and V. As shown in the last column in Table IV,
TABLE V

COMPARISON BETWEEN RESUlTS OF DifFERENT Methods FOR Block $A$ IN FIG. 3

\begin{tabular}{ccccc}
\hline $\begin{array}{c}\text { Solution } \\
\text { method }\end{array}$ & $\begin{array}{c}\text { Best solution } \\
\left(\$ 10^{6}\right)\end{array}$ & $\begin{array}{c}\text { Ave. of solutions } \\
\left(\$ 10^{6}\right)\end{array}$ & $\begin{array}{c}\text { St.dev. } \\
(\$)\end{array}$ & $\begin{array}{c}\text { Ave. time } \\
(\mathrm{sec})\end{array}$ \\
\hline Simple GA & 1.5124 & 1.5341 & 54632.81 & 72.182 \\
\hline $\begin{array}{c}\text { Proposed } \\
\text { ASSA }\end{array}$ & 1.5124 & 1.5124 & 0 & 0.473 \\
\hline
\end{tabular}

TABLE VI

SeP Results of the Proposed Method for Block $A$ in Fig. 3

\begin{tabular}{cccccc}
\hline No & $\begin{array}{c}\text { Existing } \\
\text { capacity } \\
\text { (MVA) }\end{array}$ & $\begin{array}{c}\text { Load } \\
\text { (MVA) }\end{array}$ & $\begin{array}{c}\text { New } \\
\text { capacity } \\
\text { (MVA) }\end{array}$ & $\begin{array}{c}\text { Loading } \\
(\%)\end{array}$ & $\begin{array}{c}\text { Allocated loads } \\
\text { (Zone number) }\end{array}$ \\
\hline Existing 01 & 30 & 19.65 & 30 & 65.53 & $\begin{array}{c}\text { Z 01, Z 02, Z 03, Z 04, Z 05, } \\
\text { Z 06, Z 07, Z 08, Z 11 }\end{array}$ \\
\hline $\begin{array}{c}\text { Candidate } \\
06\end{array}$ & --- & 18.38 & $2 \times 15$ & 61.27 & $\begin{array}{c}\text { Z 09, Z 10, Z 12, Z13, Z 14, } \\
\text { Z 15, Z16, Z17 }\end{array}$ \\
\hline
\end{tabular}

TABLE VII

COMPARISON BETWEEN SEP RESULTS OF DIFFERENT Methods FOR BLOCK $A$ IN FIG. 3

\begin{tabular}{ccccc}
\hline Solution method & $\begin{array}{c}\text { Best solution } \\
\left(\$ 10^{6}\right)\end{array}$ & $\begin{array}{c}\text { Ave. of solutions } \\
\left(\$ 10^{6}\right)\end{array}$ & $\begin{array}{c}\text { St.dev. } \\
(\$)\end{array}$ & $\begin{array}{c}\text { Ave. time } \\
(\mathrm{min})\end{array}$ \\
\hline Simple GA & 2.766340 & 3.89153 & 39520.3 & 18.603 \\
\hline $\begin{array}{c}\text { GA using operators } \\
\text { proposed in [22] }\end{array}$ & 2.766340 & 2.80219 & 37631.5 & 32.515 \\
\hline Proposed EA Method & 2.766340 & 2.77220 & 19752.9 & 2.249 \\
\hline
\end{tabular}

"Existing 01" has the most loading, which shows that Existing 01 is nearer to the load's center of gravity. The proposed service areas are shown in Fig. 5; although it seems that "Zone 13" is nearer to "Candidate 05," it is supplied by "Candidate 03." To understand this, it should be kept in mind that the distance criterion used in this paper is not radial; hence, Zone 13 is nearer to Candidate 03 considering (2). Obtained results of the ASSA algorithm are compared with those of the GA in Table V. The programmed GA has a binary structure and is formed according to [21]. This table indicates that the proposed ASSA algorithm not only could achieve the best solution of the GA in much less time but also could improve the average of solutions $(1.4 \%)$.

In order to find the globally optimal substation service areas of the study region, the problem is conducted using a direct search through the problem search space. The search space consists of $3^{17}$ states, and the stack-saving method is employed to reduce the computational burden [46]. Obtained results of this system - which are achieved after approximately $8 \mathrm{~h}$ of computation - are completely consistent with those proposed.

According to the obtained results of this scenario, it can be concluded that the proposed ASSA algorithm can find proper solutions in a very short time, but there is no claim on the global optimality of the solutions.

\section{B. Second Scenario}

In this scenario, the enhanced EA is conducted to solve the SEP for block $A$ in Fig. 3 and the entirety of Hamedan. Obtained SEP results for block $A$ in Fig. 3 are presented in Tables VI and VII. As shown in Table VI, the existing substation is not expanded, but a new substation is constructed; 
the new substation has 30-MVA capacity, which consists of two 15-MVA transformers. Although, according to Table II, the cost of a 30-MVA transformer is $29 \%$ less than the total cost of two 15-MVA transformers, this study investigated if when a 30-MVA transformer (instead of the two 15-MVA transformers) were to be installed in the new substation, the total expansion costs would increase by $7.4 \%$ due to more supply interruption. This indicates that significant effects of a capacity-based codification are more pronounced for the SEP problem; indeed, once reliability is considered within the SEP problem, optimal transformer configuration of each substation should also be investigated.

As the fifth column in Table VI shows, average loading percentage of substations is equal to $63.4 \%$, which demonstrates that substations would operate near their permissible loading at the end of the planning period. To evaluate the performance of the proposed method, the SEP is solved using a simple GA and with a GA, which is reinforced by new operators proposed in [22]. These operators are a mathematical crossover, a most suitable mutation, and a dual displacement mutation, which increase the computational burden but improve the solution's quality. All programs are implemented for ten independent runs, and the results are shown in Table VII. According to the presented results, the proposed algorithm not only improved the average of solutions (10\%) but also decreased the standard deviation (47\%) and the solution time (93\%), which demonstrates that the introduced method is more robust than the GAs.

In order to evaluate the performance of the proposed method in large distribution networks, SEP was investigated for the entirety of Hamedan. Obtained results are depicted in Fig. 6 and Tables VIII-X. According to Table VIII, expanding two existing substations and constructing four new ones are the clauses of proper electrification of loads within the planning horizon. While existing substations would have average loading of $58.4 \%$, new substations would operate under loading of $69.9 \%$; allocated load points are shown in Fig. 6. Considering the selected substations within a Greenfield condition, the proposed ASSA algorithm is conducted to find the substation service areas; obtained results of this case are exactly same as those presented in Fig. 6. It is empirically seen in simulations that optimal service areas of the SEP problem for 25 different test systems that are solved by the EA method are similar to those of the ASSA algorithm in 21 cases (84\%); maximum deviation of the ASSA results from the optimal solution was less than $4 \%$.

Table IX represents the comparisons between SEP results of different methods. It shows that the proposed method achieved better solutions than the other algorithms. Sensitivity analysis is also taken over the changes of network size in Table X. Considering the obtained results, the efficiency of the proposed method is more pronounced as the network becomes larger.

\section{Third Scenario}

Although the SEP investigated in recent specialized literature does not deal with reliability [17]-[27], it is considered as a

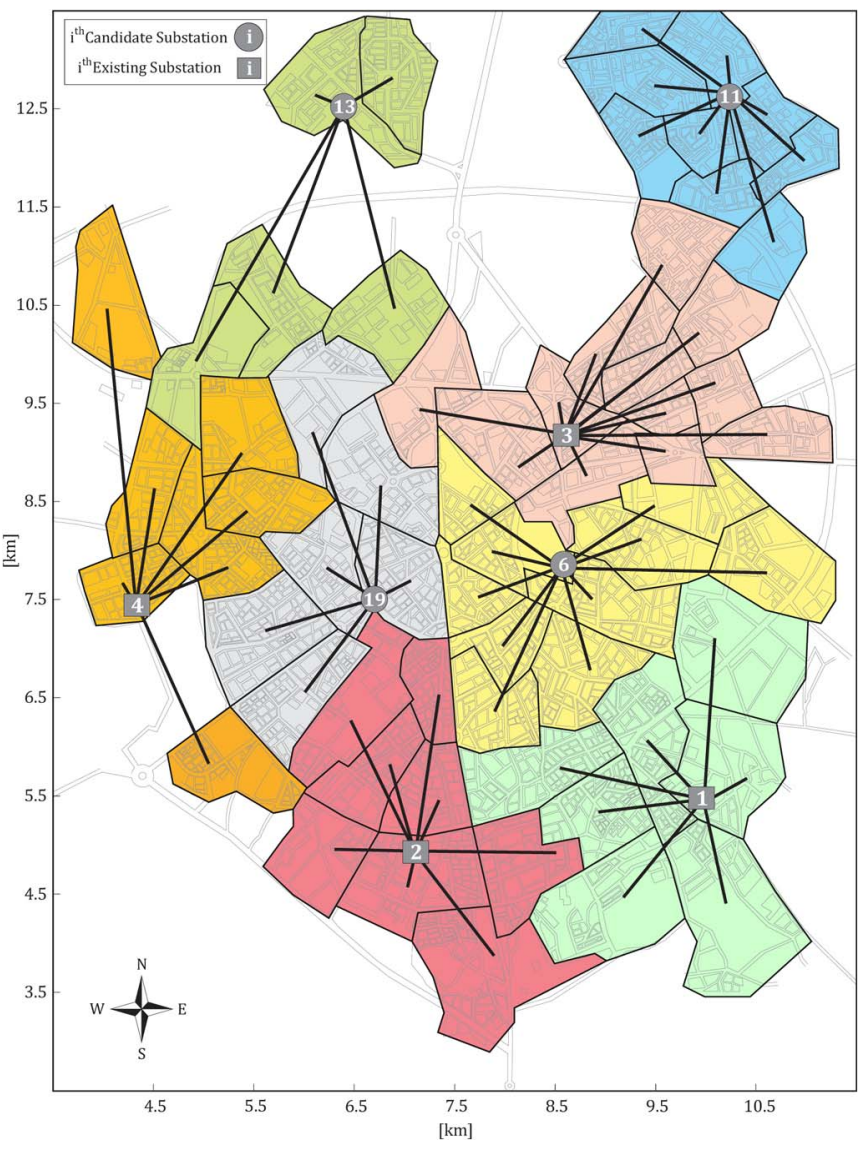

Fig. 6. Proposed SEP solution for the planning zone.

TABLE VIII

OBTAINED RESUlTS OF SEP IN FIG. 3

\begin{tabular}{lcccc}
\hline No & $\begin{array}{c}\text { Existing capacity } \\
\text { (MVA) }\end{array}$ & $\begin{array}{c}\text { Load } \\
\text { (MVA) }\end{array}$ & $\begin{array}{c}\text { New capacity } \\
\text { (MVA) }\end{array}$ & $\begin{array}{c}\text { Loading } \\
(\%)\end{array}$ \\
\hline Existing 01 & 30 & 14.235 & 30 & 47.45 \\
\hline Existing 02 & 15 & 19.719 & $2 \times 15$ & 65.73 \\
\hline Existing 03 & 15 & 18.579 & $2 \times 15$ & 61.93 \\
\hline Existing 04 & 30 & 17.533 & 30 & 58.44 \\
\hline Candidate 06 & --- & 22.480 & $2 \times 15$ & 74.93 \\
\hline Candidate 11 & --- & 11.108 & 15 & 74.05 \\
\hline Candidate 13 & --- & 8.399 & 15 & 55.99 \\
\hline Candidate 19 & --- & 22.381 & $2 \times 15$ & 74.60 \\
\hline
\end{tabular}

TABLE IX

COMPARISON BETWEEN SEP RESUlTS OF DiFFERENT METHOdS IN Fig. 3

\begin{tabular}{ccccc}
\hline Solution method & $\begin{array}{c}\text { Best solution } \\
\left(\$ 10^{6}\right)\end{array}$ & $\begin{array}{c}\text { Ave. of solutions } \\
\left(\$ 10^{6}\right)\end{array}$ & $\begin{array}{c}\text { St.dev. } \\
(\$)\end{array}$ & $\begin{array}{c}\text { Ave. time } \\
(\mathrm{min})\end{array}$ \\
\hline Simple GA & 7.529919 & 7.706688 & 242140.3 & 64.094 \\
\hline $\begin{array}{c}\text { GA using operators } \\
\text { proposed in [22] }\end{array}$ & 6.530641 & 6.868424 & 398247.8 & 243.171 \\
\hline Proposed EA Method & 6.025653 & 6.182063 & 221707.3 & 14.819 \\
\hline
\end{tabular}

TABLE $\mathrm{X}$

SENSITIVITY ANALYSIS ON SEP RESULTS BY Changing The Network Size

\begin{tabular}{ccccc}
\hline District & Results & Simple GA & $\begin{array}{c}\text { GA using operators } \\
\text { proposed in [22] }\end{array}$ & $\begin{array}{c}\text { Proposed EA } \\
\text { method }\end{array}$ \\
\hline $\begin{array}{l}\text { Block } A \text { of } \\
\text { Fig. 3 } 3\end{array}$ & Cost $\left(\$ 10^{6}\right)$ & 2.76634 & 2.76634 & 2.76634 \\
\cline { 2 - 5 } & Time $(\mathrm{min})$ & 18.603 & 32.515 & 2.249 \\
\hline \hline \multirow{2}{*}{ Fig. 3 } & Cost $\left(\$ 10^{6}\right)$ & 7.52991 & 6.53064 & 6.02565 \\
\cline { 2 - 5 } & Time $(\mathrm{min})$ & 64.094 & 243.171 & 14.819 \\
\hline
\end{tabular}


TABLE XI

OBTAINED RESULTS OF SEP IN FIG. 3 Without CONSIDERING RELIABILITY

\begin{tabular}{lcccc}
\hline No & $\begin{array}{c}\text { Existing capacity } \\
\text { (MVA) }\end{array}$ & $\begin{array}{c}\text { Load } \\
\text { (MVA) }\end{array}$ & $\begin{array}{c}\text { New capacity } \\
\text { (MVA) }\end{array}$ & $\begin{array}{c}\text { Loading } \\
(\%)\end{array}$ \\
\hline Existing 01 & 30 & 18.096 & 30 & 60.32 \\
\hline Existing 02 & 15 & 25.752 & 45 & 57.23 \\
\hline Existing 03 & 15 & 27.446 & 45 & 60.99 \\
\hline Existing 04 & 30 & 20.451 & 30 & 68.17 \\
\hline Candidate 10 & --- & 20.987 & 30 & 69.95 \\
\hline Candidate 17 & --- & 21.702 & 30 & 72.34 \\
\hline
\end{tabular}

TABLE XII

EFFECTS OF COMPONENTS UNRELIABILITY ON SEP RESUlts IN FIG. 3 (IN MiLLION \$)

\begin{tabular}{c|c|c|c|c|c}
\hline SEP & $\begin{array}{c}\text { Total } \\
\text { substation } \\
\text { costs }\end{array}$ & $\begin{array}{c}\text { Total } \\
\text { Feeder } \\
\text { costs }\end{array}$ & $\begin{array}{c}\text { Total } \\
\text { expansion } \\
\text { costs }\end{array}$ & $\begin{array}{c}\text { Supply } \\
\text { interruption }\end{array}$ & $\begin{array}{c}\text { Total SEP } \\
\text { cost }\end{array}$ \\
\hline $\begin{array}{c}\text { With } \\
\text { reliability }\end{array}$ & 3.25248 & 2.49717 & 5.74965 & 0.276003 & 6.025653 \\
\hline $\begin{array}{c}\text { Without } \\
\text { reliability }\end{array}$ & 2.55770 & 2.91650 & 5.47420 & 0.914450 & 6.388650 \\
\hline
\end{tabular}

part of the objective function in this paper. Consequently, the effects of the proposed reliability model on the SEP results in Fig. 3 are investigated in this scenario. To accomplish this, the SEP of Hamedan is solved by neglecting reliability issues modeled within the fifth term of (1) and the fourth term of (10); obtained results are shown in Tables XI and XII. As shown in Table XI, two existing substations are expanded by 30 MVA, and two new substations are constructed. In comparison with those in Table VIII, total installed capacities are the same, but fewer substations are constructed in the case of Table XI, which shows that existing substations are more expanded than those in Table VIII. Detailed data listings of costs associated with the SEP, with and without reliability, are reported in Table XII. As shown in this table, although the SEP proposed in Table XI achieved a layout with lower expansion cost than that in Table VIII (5\%), it imposes greater costs (6\%) once total costs of supply interruption are taken into account. The results presented in Tables XI and XII show that the proposed reliability model forces the SEP to construct more new substations, to decrease the feeder's length, and to use multiple transformers in each substation; it is aimed at improving the reliability level and decreasing the supply interruptions with respect to economic considerations. Accordingly, it can be used as a simple and efficient model for SEP within actual distribution networks.

Here, sensitivity analysis is carried out over the changes of EA expert initial population and EA selection rates; all programs are implemented for ten independent runs, and obtained results are presented in Tables XIII and XIV. As shown in the third row in Table XIII, the best solution and solution time associated with ROIEP $=30 \%$ is almost $10 \%, 26 \%$ better than those of ROIEP $=0$, which shows that the proposed expert initial population has significant effects on convergence of the EA. As shown in the seventh row in Table XIII, although computational burden is increased when the number of population is doubled, solution optimality is substantially improved so that the average of solutions is decreased by almost $11 \%$. This indicates that a constrained population has
TABLE XIII

Sensitivity ANALYSIS ON CHANGING EA EXPERT INITIAL POPULATIONS IN SEP RESULTS IN FIG. 3 (With Normal SELECTION STRATEGY)

\begin{tabular}{cccccc}
\hline$n_{\text {pop }}$ & $\begin{array}{c}\text { ROEIP } \\
(\%)\end{array}$ & $\begin{array}{c}\text { Best solution } \\
\left(\$ 10^{6}\right)\end{array}$ & $\begin{array}{c}\text { Ave. of solutions } \\
\left(\$ 10^{6}\right)\end{array}$ & St. dev. (\$) & $\begin{array}{c}\text { Ave. time } \\
(\mathrm{min})\end{array}$ \\
\hline \multirow{3}{*}{64} & 0 & 7.625545 & 8.157796 & 224309.5 & 56.775 \\
\cline { 2 - 6 } & 30 & 6.824596 & 7.656949 & 256212.2 & 41.775 \\
\cline { 2 - 6 } & 60 & 6.639155 & 7.314532 & 240221.4 & 35.498 \\
\hline \hline & 90 & 6.025653 & 6.714345 & 213042.7 & 23.884 \\
\hline \multirow{4}{*}{128} & 7.232807 & 7.930803 & 263433.2 & 82.324 \\
\hline & 30 & 6.657382 & 6.865535 & 219177.6 & 59.763 \\
\hline 60 & 6.025653 & 6.630737 & 227280.4 & 33.241 \\
\hline 90 & 6.025653 & 6.436542 & 198580.2 & 18.462 \\
\hline
\end{tabular}

TABLE XIV

Sensitivity ANALysis Over the Changes of EA Selection Rate in SEP RESULTS IN FIG. $3\left(n_{\text {pop }}=64\right.$, ROEIP $\left.=30 \%\right)$

\begin{tabular}{ccccc}
\hline$k_{\text {sel }}$ & $\begin{array}{c}\text { Best solution } \\
\left(\$ 10^{6}\right)\end{array}$ & $\begin{array}{c}\text { Ave. of solutions } \\
\left(\$ 10^{6}\right)\end{array}$ & St. dev. (\$) & $\begin{array}{c}\text { Ave. time } \\
(\mathrm{min})\end{array}$ \\
\hline 0 & 6.824596 & 7.656949 & 256212.2 & 41.775 \\
\hline 0.2 & 6.473921 & 7.201283 & 232416.7 & 32.010 \\
\hline 0.4 & 6.210705 & 6.736526 & 223967.4 & 24.627 \\
\hline 0.6 & 6.025653 & 6.471099 & 209831.0 & 17.203 \\
\hline 0.8 & 6.025653 & 6.182063 & 221707.3 & 14.819 \\
\hline
\end{tabular}

intensive influences on SEP results and that the proposed ASSA algorithm can bring proper constrained layouts for the problem studied here.

As introduced in Section IV, based on the EA selection rate $k_{\text {sel }}$, a set of nonelite population is separated from the initial population, and the second part of the selected chromosomes is changed by means of the ASSA algorithm. Then, the tournament technique is used to select the best configurations among new chromosomes and the preexisting ones. The effects of the proposed selection mechanism are investigated in Table XIV. It shows that once the selection rate increases, solution optimality improves and the solution time decreases, demonstrating that the proposed selection mechanism adequately affects the convergence chance to the optimal solution. It should be kept in mind, as mentioned in Section IV, that the EA is reinforced by a diversification strategy to prevent impressment of solutions in local minima. Hence, a user should note that it is empirically seen in simulations that using higher selection rates $\left(k_{\text {sel }} \geq 0.7\right)$ without incorporating a diversification strategy such as that proposed in [14] may cause strong attraction to local minima.

\section{CONCLUSION}

This paper has presented a new solution technique for the SEP problem by incorporating a hybrid heuristic and evolutionary algorithm. The introduced deterministic heuristic algorithm finds a proper solution for substation service areas under Greenfield condition. Moreover, it is employed to generate expert initial populations and a new selection strategy, which enhance the EA to efficiently solve the SEP problem. In comparison with the archived specialized literature conducted on SEP, the developed model not only considers all prevalent cost indices but also the effects of supply interruptions. The developed algorithm is conducted on an actual large-scale network and 
four benchmark test systems, and intensive testing is carried out in several scenarios to validate the new approach. As the simulation results illustrate, the proposed method is robust and achieves proper solutions in less solution time than the studied algorithms. Therefore, it can be used as an effective tool for SEP within an actual large-scale distribution network. In addition, the proposed ASSA algorithm is simple from the programming point of view and can be used with different objective functions without loss of generality.

Further research may be conducted on SEP considering system restoration under contingencies and a new method for distribution feeder routing by incorporating the ASSA algorithm.

\section{REFERENCES}

[1] T. Gonen, Electric Power Distribution System Engineering. New York, NY, USA: McGraw-Hill, 1986.

[2] H. L. Willis, Power Distribution Planning Reference Book, 2nd ed. New York, NY, USA: Marcel Dekker, 2004.

[3] I. J. Ramirez-Rosado and T. Gonen, "Pseudodynamic planning for expansion of power distribution systems," IEEE Trans. Power Syst., vol. 6, no. 1, pp. 245-254, Feb. 1991

[4] C. M. Domingo, T. G. S. Roman, A. Sanchez-Miralles, J. P. P. Gonzalez, and A. C. Martinez, "A reference network model for large-scale distribution planning with automatic street map generation," IEEE Trans. Power Syst., vol. 26, no. 1, pp. 190-197, Feb. 2011.

[5] D. T.-C. Wang, L. F. Ochoa, and G. P. Harrison, "Modified GA and data envelopment analysis for multistage distribution network expansion planning under uncertainty," IEEE Trans. Power Syst., vol. 26, no. 2, pp. 897-904, May 2011.

[6] R. C. Lotero and J. Contreras, "Distribution system planning with reliability," IEEE Trans. Power Del., vol. 26, no. 4, pp. 2552-2562, Oct. 2011.

[7] S. Haffner, L. F. A. Pereira, L. A. Pereira, and L. S. Barreto, "Multistage model for distribution expansion planning with distributed generation-Part I: Problem formulation," IEEE Trans. Power Del., vol. 23, no. 2, pp. 915-923, Apr. 2008.

[8] M. Lavorato, M. J. Rider, A. V. Garcia, and R. Romero, "A constructive heuristic algorithm for distribution system planning," IEEE Trans. Power Syst., vol. 25, no. 3, pp. 1734-1742, Aug. 2010.

[9] J. C. Moreira, E. Míguez, C. Vilachá, and A. F. Otero, "Large-scale network layout optimization for radial distribution networks by parallel computing," IEEE Trans. Power Del., vol. 26, no. 3, pp. 1946-1951, Jul. 2011.

[10] J. Salehi and M. Haghifam, "Long term distribution network planning considering urbanity uncertainties," Elect. Power Energy Syst., vol. 42, no. 1, pp. 321-333, Nov. 2012.

[11] A. M. Cossi and J. R. S. Mantovani, "Integrated planning of electric power distribution networks," IEEE Latin Amer. Trans., vol. 7, no. 2, pp. 203210, Jun. 2009.

[12] A. Navarro and H. Rudnick, "Large-scale distribution planning-Part I: Simultaneous network and transformer optimization," IEEE Trans. Power Syst., vol. 24, no. 2, pp. 744-751, May 2009

[13] S. Najafi, S. H. Hosseinian, M. Abedi, A. Vahidnia, and S. Abachezadeh, "A framework for optimal planning in large distribution networks," IEEE Trans. Power Syst., vol. 24, no. 2, pp. 1019-1028, May 2009.

[14] A. M. Cossi, R. Romero, and J. R. S. Mantovani, "Planning of secondary distribution circuits through evolutionary algorithms," IEEE Trans. Power Del., vol. 20, no. 1, pp. 205-213, Jan. 2005.

[15] J. M. Nahman and D. M. Peric, "Optimal planning of radial distribution networks by simulated annealing technique," IEEE Trans. Power Syst., vol. 23, no. 2, pp. 790-795, May 2008.

[16] S. Singh, T. Ghose, and S. K. Goswami, "Optimal feeder routing based on the bacterial foraging technique," IEEE Trans. Power Del., vol. 27, no. 1, pp. 70-78, Jan. 2012.

[17] E. Masud, "An interactive procedure for sizing and timing distribution substations using optimization techniques," IEEE Trans. Power App. Syst., vol. PAS-93, no. 5, pp. 1281-1286, Sep. 1974.

[18] D. Crowford and S. Holt, "A mathematical optimization technique for locating and sizing distribution substations and deriving their optimal service areas," IEEE Trans. Power App. Syst., vol. PAS-94, no. 2, pp. 230 $235,1975$.
[19] G. Thompson and D. Wall, "A branch-and-bound model for choosing optimal substation locations," IEEE Trans. Power App. Syst., vol. PAS-100, pp. 2683-2688, May 1981.

[20] D. Hongwei, Y. Yixin, H. Chunhua, W. Chengshan, and G. Shaoyun, "Optimal planning of distribution substation locations and sizes-Model and algorithm," Elect. Power Energy Syst., vol. 18, no. 6, pp. 353-357, Aug. 1996

[21] M.-R. Haghifam and M. Shahabi, "Optimal location and sizing of HV/MV substations in uncertainty load environment using genetic algorithm," Elect. Power Syst. Res., vol. 63, no. 1, pp. 37-50, Aug. 2002.

[22] M. H. Sepasian, H. Seifi, A. A. Foroud, S. H. Hosseini, and E. M. Kabir, "A new approach for substation expansion planning," IEEE Trans. Power Syst., vol. 21, no. 2, pp. 997-1004, May 2006.

[23] S. Najafi, A. Vahidnia, H. Hatami, and S. Abachizadeh, "Optimal distribution substation locating in large distribution systems," Transmiss. Distrib. Conf. Expo., Asia and Pacific, pp. 1-6, 2009.

[24] H. K. Temraz and M. M. A. Salama, "A planning model for sitting, sizing and timing of distribution substations and defining the associated service area," Elect. Power Syst. Res., vol. 62, no. 2, pp. 145-151, Jun. 2002.

[25] T. H. M. El-Fouly, H. H. Zeineldin, E. F. El-Saadany, and M. M. A. Salama, "A new optimization model for distribution substation sitting, sizing, and timing," Elect. Power Syst. Research, vol. 30, no. 5, pp. 308-315, Jun. 2008.

[26] H. M. Khodr, J. A. Melian, A. J. Quiroz, D. C. Picado, J. M. Yusta, and A. J. Urdaneta, "A probabilistic methodology for distribution substation location," IEEE Trans. Power Syst., vol. 18, no. 1, pp. 388-393, Feb. 2003.

[27] K. Yahav and G. Oron, "Optimal location of electrical substation in regional energy supply systems," in Proc. IEEE EEIS, Jerusalem, Israel, 1996, pp. 307-310.

[28] E. Míguez, J. Cidrás, E. Díaz-Dorado, and J. L. García-Dornelas, "An improved branch-exchange algorithm for large scale distribution network planning," IEEE Trans. Power Syst., vol. 17, no. 4, pp. 931-936, Nov. 2002.

[29] G. A. Jiménez-Estévez, L. S. Vargas, and V. Marianov, "Determination of feeder areas for the design of large distribution networks," IEEE Trans. Power Del., vol. 25, no. 3, pp. 1912-1922, Jul. 2010.

[30] C. L. Lawrence, K. K. Suresh, and C. S. Jacqueline, "Planning substation capacity under single-contingency scenario," IEEE Trans. Power Syst., vol. 10, no. 3, pp. 1442-1447, Aug. 1995.

[31] D. E. Kieso, J. J. Weygandt, and T. D. Warfield, Intermediate Accounting Hoboken, NJ, USA: Wiley, 2009, ch. 11.

[32] R. Billinton and R. N. Allan, Reliability Evaluation of Power Systems. New York, NY, USA: Springer-Verlag, 1996.

[33] X. L. Mazur, R. W. Allen, and D. R. Swatek, "Specifying transformer winter and summer peak-load limits," IEEE Trans. Power Del., vol. 20, no. 1, pp. 185-190, Jan. 2005.

[34] P. M. Anderson, B. L. Agrawal, and J. E. Van Ness, Subsynchronous Resonance in Power Systems. Hoboken, NJ, USA: Wiley, 1999.

[35] A. A. Chowdhury, L. Bertling, and D. E. Custer, "Determining distribution substation transformer optimal loadings using a reliability cost-benefit approach," in Proc. 9th Int. Conf. Probability Methods Appl. Power Syst., Stockholm, Sweden, 2006, pp. 1-9.

[36] F. G. Montoya, R. L. Banos, C. Gil, A. Espinc, A. Alcayde, and J. Gomez, "Minimization of voltage deviation and power losses in power networks using Pareto optimization methods," Eng. Appl. Artif. Intell., vol. 23, no. 5, pp. 695-703, Aug. 2010.

[37] C. Magele, M. Jaindl, A. K. Stinger, and W. Renhart, "Niching evolution strategy finding global and Pareto optimal solutions," Int. J. Comp. Math. Elect. Electron. Eng., vol. 29, no. 6, pp. 1514-1523, 2010.

[38] A. Aho and J. Ullman, Foundations of Computer Science. San Francisco, CA, USA: Freeman, 1992, ch. 4, p. 158.

[39] S. Arora and B. Barak, Computational Complexity: A Modern Approach. Cambridge, U.K.: Cambridge Univ. Press, Apr. 2009.

[40] D. B. Fogel, Evolutionary Computation: Toward a New Philosophy of Machine Intelligence, 3rd ed. Piscataway, NJ, USA: IEEE press, 2006.

[41] [Online]. Available: http://en.wikipedia.org/wiki/Hamedan

[42] N. G. Boulaxis and M. P. Papadopoulos, "Optimal feeder routing in distribution system planning using dynamic programming technique and GIS facilities," IEEE Trans. Power Del., vol. 17, no. 1, pp. 242-247, Jan. 2002.

[43] [Online]. Available: http://faculty.bus.olemiss.edu/balidaee/

[44] [Online]. Available: http://smmazhari.blogfa.com

[45] L. Wang, S. Wang, and Y. Xu, "An effective hybrid EDA-based algorithm for solving multidimensional knapsack problem," Expert Syst. Appl., vol. 39, no. 5, pp. 5593-5599, Apr. 2012.

[46] E. Horowitz and S. Sahni, Fundamentals of Data Structures. Rockville, MD, USA: Computer Science, 1976, pp. 81-112. 


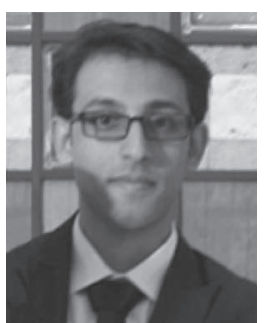

Seyed Mahdi Mazhari (S'12) received the B.S. (Hons.) degree in electrical engineering from the University of Birjand, Birjand, Iran, in 2010 and the M.S. (Hons.) degree in electrical engineering from the University of Tehran, Tehran, Iran, 2012. $\mathrm{He}$ is currently working toward the Ph.D. degree at Amirkabir University of Technology, Tehran.

$\mathrm{He}$ is also currently a Research Associate with the Research Center of Power System Operation and Planning Studies, University of Tehran. His research interests include planning of electric power distribution and transmission systems, power system operation, power system real-time analysis, and artificial intelligence applications to power system optimization problems.

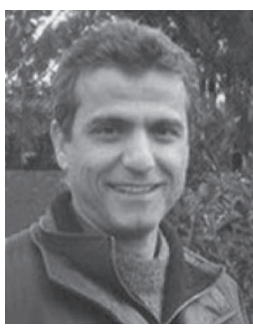

Hassan Monsef received the B.Sc. degree from Sharif University of Technology, Tehran, Iran, in 1986, the M.Sc. (Hons.) degree from the University of Tehran, Tehran, in 1989, and the Ph.D. degree from Sharif University of Technology in 1996, all in power engineering.

Since 1996, he has been with the University College of Engineering, School of Electrical and Computer Engineering, University of Tehran, where he is currently an Associate Professor. His research interests are power system operation under deregulation, reliability of power system, electric power quality, and power system protection.

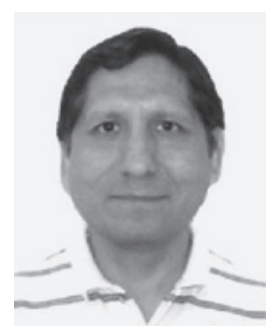

Rubén Romero (M'93-SM'08) received the B.Sc. and P.E. degrees from the National University of Engineering, Lima, Perú, in 1978 and 1984, respectively, and the M.Sc. and Ph.D. degrees from the Universidade Estadual de Campinas, Campinas, Brazil, in 1990 and 1993, respectively.

He is currently a Professor of electrical engineering with the Universidade Estadual Paulista "Julio de Mesquita Filho," Ilha Solteira, Brazil. His research interests include methodologies for the optimization, planning, and control of electrical power systems; applications of artificial intelligence in power system; and operations research. 